\title{
Effective Use of United States Foreign Aid to Fund Infrastructure Projects
}

\author{
Kevin McGuirk ${ }^{1}$, Anoop Sattineni ${ }^{2}$ and Wesley Collins ${ }^{2}$ \\ 1 United States Army Corps of Engineers, USA \\ 2 Auburn University, Auburn, USA
}

\begin{abstract}
Foreign aid is one of the tools the U.S. Government uses to promote stability and economic growth around the world. U.S. Foreign assistance to the region is currently guided by the U.S. Strategy for Central America which was announced in 2015. According to the U.S. Agency for International Development (USAID), average U.S. foreign aid to the Northern Triangle countries exceeded $\$ 400$ million per year over the ten year period between 2008 and 2018. During this period approximately 10\% of U.S foreign aid was used to fund infrastructure projects. Despite recent investment, the World Economic Forum ranks the infrastructure of the three countries in the Northern Triangle in the bottom half of all countries surveyed. With continued investment and unremarkable results over the past decade, it is useful to examine the efficiency of the investments and ensure available funding is effectively invested. USAID is the primary conduit for the distribution of US foreign aid. The United States Government works through several federal agencies outside the borders of the United States and much of this work is focused on security and military development in foreign countries. The U.S. Army Corps of Engineers (USACE) is one such agency and is currently managing overseas operations around the world. The main overseas mission of USACE offices appears to be in line with the development of military construction projects for foreign governments. In this paper, researchers examine the basic tenets of the proposed arrangements for the US to engage in funding infrastructure projects in foreign countries to alleviate un-employment related issues. The said funding also enhances the construction talent in countries receiving such funding. This is a qualitative research exploring the success of the proposed funding in the Norther Triangle region of Central America. Results from interviewing key personnel and literature review reveal that this opportunity can be improved to the benefit of all parties.
\end{abstract}

(C) 2020 The Authors. Published by Budapest University of Technology and Economics \& Diamond Congress Ltd Peer-review under responsibility of the Scientific Committee of the Creative Construction Conference 2020.

Keywords: foreign aid, infrastructure, Northern Triangle, USACE, USAID

\section{Introduction}

The United States Government is currently struggling to address an influx of refugees seeking asylum at its southern border. Immigration has a long history as a volatile political issue in the United States and around the world. A significant portion of the people seeking asylum around the world choose to leave their native country as a result of war or some form of natural disaster. Many of the refugees coming to the United States southern border are arriving from the Central American countries of Guatemala, Honduras and El Salvador which collectively make up a region known as the Northern Triangle. This region has struggled recently with political economic and social unrest which has contributed to a mass migration. The United States Government currently spends Billions of dollars on foreign aid around the world [1]. This research will provide an in depth review of the portion of that aid that is directed towards infrastructure projects in the Northern Triangle region. Despite recent investment, the World Economic Forum ranks the infrastructure of the three countries in the Northern Triangle in the bottom half of all countries surveyed 
[2]. With continued investment and unremarkable results over the past decade, it is useful to examine the efficiency of the investments and ensure available funding is effectively invested. USAID is the primary conduit for the distribution of US foreign aid. This agency works through the Department of State to identify and distribute funding through Mission Offices established in developing countries. The United States Government works through several federal agencies outside the borders of the United States and much of this work is focused on security and military development in foreign countries [1]. The U.S. Army Corps of Engineers (USACE) is one such agency and is currently managing overseas operations around the world. The main overseas mission of USACE offices appears to be in line with the development of military construction projects for foreign governments. However, USACE also has a mission that includes the development of water resources, flood risk management, navigation and infrastructure and environmental stewardship. This mission is in line with the stated goal of infrastructure development in this region. With existing expertise in the identification, award and execution of infrastructure projects, USACE may be in a unique position to execute studies that ensure existing funding is efficiently utilized. Such oversight could provide a significant impact on the value added by infrastructure investment providing a greater benefit to the host nation and the U. S. taxpayer. This research will explore the current efforts of United States Agency for International Development (USAID) in the role that agency plays in the distribution of US foreign aid for the development of infrastructure projects in Northern Triangle Countries. In addition this research will explore the role that other US Federal agencies such as USACE can play in the identification, award and execution of infrastructure projects in Central America.

\section{Literature review}

The distribution of U.S. foreign aid is currently governed by the 1961 Foreign Assistance Act which established the United States Agency for International Development as a sister agency to the United States Department of State and attempted to streamline the government's efforts to provide assistance around the world[1]. Prior to 1961 the first large scale use of foreign aid by the United States Government was when President Hoover created the Commission for the relief of Belgium (CRB) at the onset of World War I in 1914. The goal of this effort was to combat food shortages in German occupied Belgium and Northern France. Following World War I, the United States Food Administration provided millions of impacted civilians with food.

Following World War II the United States Government used international development as a tool for foreign policy with the Marshall Plan. This effort diverted $\$ 13$ billion in aid to allow Europe to rebuild its infrastructure and strengthen its economy. At the beginning of the Cold War, in 1949, President Truman proposed an international development assistance program. The goal was to reduce poverty, increase production and combat communism in developing countries. The Foreign Assistance Act (FAA) of 1961 created USAID with a mission to promote democratic values abroad and advance a free, peaceful and prosperous world. USAID was tasked with leading the United States Government's international development and disaster assistance through partnerships and investment. President Kennedy also launched the Peace Corps the same year. The overall intent of these actions was to spread the goodwill and positive image of the US government around the world. The FAA underwent several changes throughout the 1970 s as the nation focused on prioritizing food and healthcare when assisting foreign nations. The 1980s largely continued the focus on food and healthcare with some large high profile events such as the Live Aid concert where celebrities were engaged to help raise awareness it issues of hunger in developing nations.

The 1990s saw a major shift in US foreign policy with the end of the Cold War. USAID's top priority shifted to sustainable development and a focus on helping nations become self-sufficient. The events of September 11, 2001 created an extra urgency around foreign aid as a means of creating stability. Development of foreign countries was now seen as central to US national security. This period saw the creation of The President's Emergency Plan for AIDS Relief and the Millennium Challenge Corporation in 2003 and 2004 respectively. Today we define aid as the unilateral transfer of U.S. resources by the U.S. Government to or for the benefit of foreign entities. These resources include more than goods and funding. Aid can often take the form of technical assistance, educational programming, healthcare and other services. Foreign 
governments are not the only recipients of this aid. Local businesses, charitable groups, international organizations and other nongovernmental organizations are all potential targets for U.S. foreign aid. Over the years, there have been a variety of strategic and humanitarian goals of U.S. foreign aid. However, there has been an overarching theme of using aid to address crises, promote security and encourage selfsufficiency through development.

\section{Research methodology}

The research used the qualitative approach focusing on structured interviews. This process allowed individual experience and situational knowledge to be collected and analysed. A pilot interview was conducted using one former USAID and State Department employee and one current construction manager with experience executing federally funded construction projects. The questions were revised based on feedback form pilot interview and administered through written interview questions. The personnel considered for the interview were involved in the selection, award and execution of infrastructure projects associated with USAID mission offices across Latin America and the Caribbean. Project sizes that were under the supervision of the interviewees ranged from small local projects valued under $\$ 100,000$ to large scale multi-year national projects valued over $\$ 50,000,000$.

\section{Results}

The interview questions were grouped and ordered into three main sections. The first group of questions focused on the role of the interviewee within the organization and the role of the Mission Office in the execution of infrastructure projects funded through US foreign aid. The second area of focus was the role the office or individual played in the contract and construction management of infrastructure projects. This area also focused on gaining an understanding of the selection process to identify potential projects. The final section of the interview included a focus on how each office used resources from other federal agencies and selected projects that fit into the overall goals of larger regional programs. This section was intended to provide a better picture on how the office operates within the larger framework of the US Government. A total of 11 participants were interviewed in this research.

\subsection{Content analysis}

Including the subparts of each question, there were sixteen unique questions for each of the eleven participants to answer. Many of the subparts of questions were designed to build off previous responses and provide for the interviewee to expand on previous answers. This interview design promoted some repetitive information and assisted in the development of some overriding themes. As described previously, the questions were divided into sections and will be analysed here in the same sections.

\subsubsection{Personnel data}

In describing the scale of the projects $72 \%$ of subjects used some form of the phrase 'small scale'. In addition, more than a quarter of respondents (27\%) made reference to the use of infrastructure projects as support or supplemental to other program goals. These questions did not specifically ask about the size or use of the funded infrastructure projects. Infrastructure projects appear to be seen as support to other program goals instead of potential vehicles to drive economic improvement. Despite referencing small scale projects, the respondents did identify several sectors in which infrastructure work was being performed in the subject countries. Figure 1 above identifies different types of infrastructure projects and shows the percentage of respondents that identified each sector. In discussing the overall involvement of each subject office in the execution of infrastructure projects, the respondents were ask to identify if they were involved in construction management aspects or funding and procurement of infrastructure projects. In most cases respondents answered this question to identify the overall office involvement in the process rather than their individual involvement. 


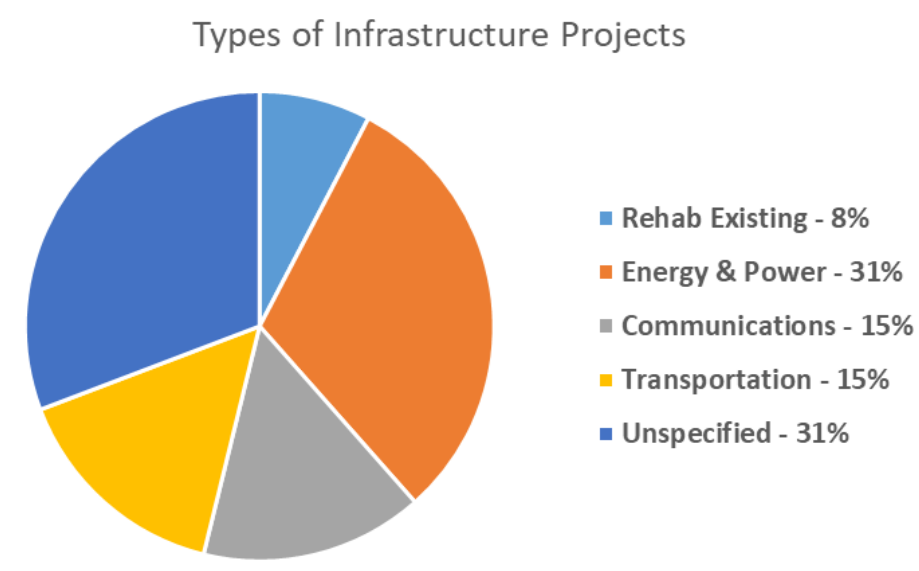

Figure 1. Types of infrastructure projects referenced

The data collected indicated that $54 \%$ of respondents identified their office as not being involved in the construction management process, as shown in figure 2. Additionally, many of the respondents use contract vehicles to manage construction activities rather than using agency personnel. The final question in this section identifies $100 \%$ of respondents as not working with other federal agencies to manage construction activities. This result is unexpected and may indicate that an agency wide policy is in place requiring that funding be used only through USAID. More research should be conducted to determine the accuracy of this information and the reasoning behind the response.

Office Involvement with Infrastructure Projects

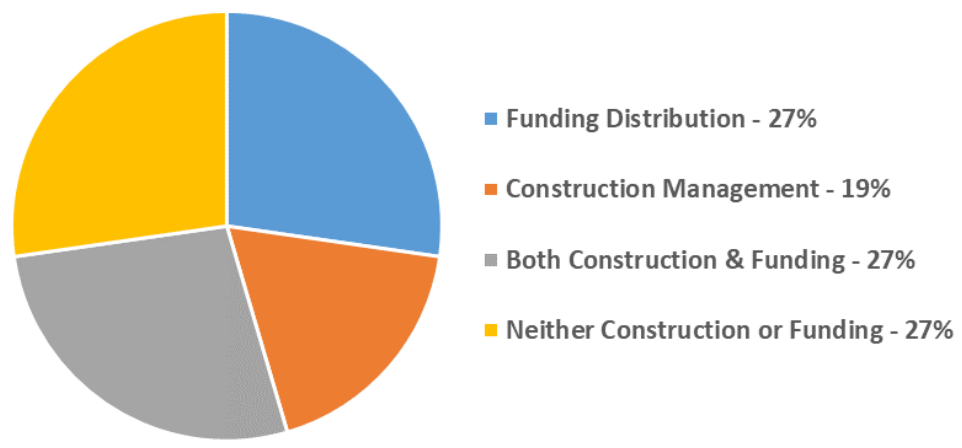

Figure 2. Office role in project execution

\subsubsection{Project execution data}

Three of the respondents did not indicate a level of involvement, the remaining respondents either focused on their own personal experience or identified a USAID policy that identifies the Agreement Officer (AO) as the authorized individual responsible for contracting agreements with new construction projects. In both cases, responses were very much influenced by USAID agency policy. The data shows that local governments and the private sector play an external role in identifying projects to USAID. In addition, USAID does utilize some technical expertise to identify and fund some projects. The information gathered supports the general position that respondents were satisfied with current levels of infrastructure investment but feel the subject countries would benefit from additional funding. Interviewees confirmed that once projects were identified, environmental reviews were required to allow the project to proceed.

All of the respondents confirmed that USAID followed federal contracting guidelines. One critical issue in the execution of federal contracts is the ability to execute contract modifications. Without convenient access to a contracting officer, minor construction issues have the potential to create huge delays, potentially stopping progress. However, USAID respondents indicated that access to contracting decision makers is not an issue, even in the sometime remote areas that USAID projects are executed. 
Interviewees were asked about performance metrics in the execution of USAID infrastructure projects. Over $45 \%$ of respondents used the question to identify how overall offices are rated. These respondents discussed the number of projects completed and renovated. As discussed in the literature review section of this paper, there is not an agreed upon method to measure the success of foreign aid. The benefits may not be evident in analysing numbers of projects or population impacted. The intent here is to see if standard construction metrics such as schedule reviews or quality control are being implemented so the projects do not experience cost or schedule growth due to mismanagement. Some responses did indicate the use of contracting measures to manage construction, however, none of the responses referenced standard construction tools to ensure project delivery.

\subsubsection{Program level data}

Finally, participants were asked about how individual offices fit into the larger structure of the United States strategy for the region. The intent of this line of questioning was to determine if infrastructure projects are identified in order to support larger program and regional goals, specifically the stated strategy of the United States Government in Central America. Responses from all offices noted that projects are in line with regional goals. Most of the respondents choose not to elaborate on their responses by giving examples of how projects are selected to meet the goals of regional programs. The final question addressed interagency coordination referencing some of the other agencies or organizations involved in the distribution of United States foreign aid. Here again respondents did not provide a large amount of detail in the responses. Generally the responses indicated that projects were coordinated on an activity implementation level but not a funding distribution level. Respondents referenced program level coordination, however, two of those respondents were in positions that did not make program level decisions.

This section of questioning provides an example where the requirement to submit written questions and answers limited the ability of the interviewer to pull more information out of the responses. It is also possible that the respondents were experiencing fatigue at the end of the interview and simply rushed to complete the responses. These limitation will be discussed further in the final chapter of this research.

Overall the responses confirm that individual mission offices are aware and do track larger regional goals but they do not provide any significant insight into how individual infrastructure projects are selected based on larger regional goals. Similarly, mission offices confirmed that they are engaged with other United States Federal Agencies. However, the responses do not provide insight into how the agencies work together to effectively spend U.S. foreign aid money to accomplish regional goals.

\subsection{Thematic analysis}

Three predominant themes were identified in the analysis of the data collected in this research. The three themes are: Limited use of infrastructure projects, a focus on using existing USAID agency policies and procedures and limited coordination within US Government Agencies.

\subsubsection{Limited infrastructure investment}

One of the main themes identified through analysis of the data appears to be the limited execution of infrastructure projects. While funding data indicates that the subject countries have executed some large multi-year infrastructure projects, the majority of the infrastructure funding over the past ten years is used to fund small scale renovations of existing infrastructure. Respondents were asked to describe the role their specific mission plays in the distribution of funding to support infrastructure projects as well as the types of projects typically funded in their respective countries. Responses to these questions referenced small scale projects that are required to compliment other projects and overall program goals. Respondents described current infrastructure programs as 'extremely minimal and limited' while describing projects that involve rehabilitation and repairs to existing structures.

Responses also reinforce the idea that subject countries would generally benefit from an increase in infrastructure funding. While these responses were somewhat muted and noted that needs were largely met, they also indicated that subject countries would benefit from additional funding. As noted in the 
literature review section, infrastructure development is a stated goal of the US strategy for Central America. Concerning the use of environmental reviews, results did not indicate that USAID is actively using such studies to identify projects but rather as part of the analysis of a project that has already been identified. This supports the possibility that some projects may not be identified and therefor may not receive funding. While the data collected in this question does not confirm that projects are left unidentified, it suggests that reviews and studies could be used differently by federal agencies in an attempt to identify potential projects. Further research would be necessary to confirm this hypothesis.

\subsubsection{Existing agency policies}

When analysing the collected data with a focus on construction management and metrics the respondents often deferred to references of existing USAID policies and procedures. Participants were questions to determine if qualified personnel are involved in the management of construction activities. The requirements laid out in USAID's Automated Directives System are highlighted in the literature review chapter of this research and identify policies and procedures to minimize construction risk.

Respondents provide extensive references to the Automated Directives System (ADS) which contains the organization and functions of USAID along with policies and procedures that guide the Agency's programs and operations. When addressing oversight of construction activities, respondents specifically referenced ADS chapter 303 - USAID Implementation of Construction Activities and ADS Chapter 201 - Construction Risk Management. Program managers involved in this study consistently referenced the requirements of ADS in responses.

While this information is useful in the context of how individual mission offices manage construction projects, it is important to relate these responses to the responses to questions relevant to the volume of work responding offices execute. Responding offices generally indicated that infrastructure projects were a small percentage of the aid projects typically funded. As such, the offices may be using published agency policies to indicate how they would manage projects if the volume of infrastructure work were to increase. This hypothesis is not tested in the data collected in this research and may be a topic for further study.

\subsubsection{Federal agency coordination}

The subject of interagency coordination was a focus of two of the questions in the interview. This theme is a main focus of this research and can provide a first-hand account of how effectively the US Federal Government works across agencies when operating in a foreign country.

One question asked the respondent to provide direct information regarding how USAID works with other US federal agencies in the management of construction activities. Another question was more focused on the coordination of the distribution of funding across agencies. In both questions the responses were unanimous. It is clear from the data collected that USAID will coordinate the distribution of funding with other agencies to meet regional goals but does not coordinate or work with other agencies to manage construction activities.

\section{Conclusions}

There were three main themes identified in the data collected during this research. The first overriding theme is the limited use of infrastructure development. The second theme was the use of standard policies in the management of construction activities. The final theme was the inadequate coordination between United States Government Agencies. Recommendations for each of the three themes is outlined below.

\subsection{Funding levels}

Data collected strongly suggests that while infrastructure projects are funded, most countries would benefit from additional infrastructure funding, as evidenced in literature [3]. This statement is valid in most areas of the world. Even in developed countries like the United States, there is a continuous need to reinvest and support infrastructure projects. This is highlighted through recent news of issues with drinking water in Flint, Michigan and the continued low ratings for the condition of bridges in the United States issued by the American Society of Civil Engineers. 
Many opponents would argue that the United States Government should focus on these internal infrastructure issues instead of spending money on the shortcomings of infrastructure in developing nations. This research did not collect data or make recommendations on the overall funding levels of foreign aid. However, the data collected does confirm that a small percentage of the overall foreign aid budget is directed towards infrastructure projects. This is true across Latin American and the Caribbean region despite the fact that infrastructure investment is a key element of the 2015 Strategy for Central America and the Alliance four Prosperity Plan. While most respondents indicated that appropriate levels of funding did exist, they also noted that additional funding would be of value. This statement is supported by data gathered on the percentages of total foreign aid used on infrastructure projects [4]. This data shows that in the Northern Triangle Countries, less than $1 \%$ of the foreign aid budget is directed to infrastructure projects in most years [5],[6],[7].

The data in this research did not identify a strong force within the existing organization of the United States Federal Government that is championing the use of foreign aid on infrastructure projects. There appears to be an opportunity to reallocate some existing funding to study and identify potential infrastructure projects. However, without an organizational focus on infrastructure issues, these projects are not likely to be identified. If infrastructure investment is important enough to be a stated goal of the regional strategy, there needs to be a central focus within USAID to study and recommend potential projects. As infrastructure development is a key focus of the regional strategies developed by the Northern Triangle Countries and the United States Government, infrastructure spending should be a larger focus of foreign aid projects.

\subsection{Existing agency policies}

Responses referenced several United States and USAID agency publications including the Federal Acquisition Regulation (FAR), USAID Acquisition Regulation (AIDAR) and Automated Directives System (ADS). These references are largely focused on the acquisition process. References to construction management are largely absent in these standards. While data indicates that USAID engineers are involved in some construction management activities, these functions are limited. Responses also indicate that there is an established process in place to manage active construction projects and this system is used on all projects. While standardization is necessary to maintain a consistent product, there is risk in a failure to adapt to the unique conditions that may exist in the construction environment. While many of the respondents were not involved in the field level management of construction projects, it is still notable that project specific plans were not mentioned in the responses provided. Chapter 2 of this research touches on the difficulty in assessing success of a foreign aid project. There are a myriad of factors that can impact these projects and many of these factors will be unique to individual projects. USAID appears to be effectively applying standards across construction projects but not focused on developing project specific plans to address site specific construction risks.

Based on the information gathered, traditional construction metrics such as schedule reviews, quality control and safety statistics are not tracked on projects receiving foreign aid. Instead, metrics focus on the number of structures rehabilitated or repaired and what value is being received for the number of dollars provided. The data suggests that there is a lack of oversight in the actual construction phase of infrastructure projects. Without such oversight, the potential exists for projects to be less efficient. Providing organizational standards for construction activities across USAID could result in a more effective use of existing funding.

\subsection{Inadequate coordination}

Data collected strongly suggests that projects and funding are not coordinated with other Federal Agencies within the United States Government. USAID respondents indicated that mission offices do identify projects based on the goals of larger regional strategies. However, construction does not appear to be coordinated with other agencies. Funding through USAID represents a significant percentage of overall foreign aid funding, there are other organizations and agencies with robust aid programs in these same countries. The projects do not appear to be coordinated between organizations at a local level. 
Organizations such as the Millennium Challenge Corporation (MCC) engage and assist foreign countries in soliciting and awarding public-privet partnerships, grants and other program procurement methods to be administered by partner countries. Currently MCC is engaged with the government of Guatemala with the Guatemala Threshold Program. This is a $\$ 28$ Million grant program working in part to stimulate more private funding for infrastructure projects. The Government of Honduras has a similar \$15.5 Million grant to create more effective public-private partnerships in the country. In El Salvador MCC is working with the government through a $\$ 277$ Million grant designed to enhance the country's competitiveness and productivity through an integrated set of investments in infrastructure education and public-privet partnerships. Data collected in this research suggests that USAID is not engaged with MCC in any of these efforts. While respondents did indicate that funding was coordinated with other government agencies, there was no involvement across agency lines in the management of construction activities. In addition to organizations such as MCC, the United States Army Corps of Engineers has an extensive network of offices involved in construction activities across Latin America and the Caribbean. The USACE program has construction offices in two of the three Northern Triangle countries as well as extensive contracting and engineering support with reach-back capabilities in the United States. The USACE program does not currently work with USAID to identify or manage projects. Several of the responses from USAID mission offices indicated that engineering and construction support are often awarded as part of a construction contract due to lack of resources. With clear construction management options currently functioning in the region, the United States Government needs to be more aware of its own existing resources. The figure below illustrates the existing footprint of USACE in Latin America. The USACE program represents an existing construction management element within the framework of the Federal Government that could be employed to implement some of these recommendations.

\section{References}

[1] "U.S. Agency for International Development." Accessed August 21, 2019. https://www.usaid.gov/.

[2] Schwab, Klaus. "The Global Competitiveness Report 2019," n.d., 666, The World Economic Forum, http://www3.weforum.org/docs/WEF_TheGlobalCompetitivenessReport2019.pdf

[3] "Does Infrastructure Investment Lead to Economic Growth or Economic Fragility? Evidence from China." Oxford Review of Economic Policy 32, no. 3 (January 1, 2016): 360-90. https://doi.org/10.1093/oxrep/grw022.

[4] "El_Salvador_External_Fact_Sheet_July_2018.Pdf." Accessed August 21, 2019. https://www.usaid.gov/sites/default/files/documents/1862/El_Salvador_External_Fact_Sheet_July_2018.pdf.

[5] Lawson, Marian L, and Emily M Morgenstern. "Foreign Aid: An Introduction to U.S. Programs and Policy." Foreign Aid, n.d., 36.

[6] Ansar, Atif, Bent Flyvbjerg, Alexander Budzier, and Daniel Lunn. "Does Infrastructure Investment Lead to Economic Growth or Economic Fragility? Evidence from China." Oxford Review of Economic Policy 32, no. 3 (January 1, 2016): 360-90. https://doi.org/10.1093/oxrep/grw022.

[7] Ahsan, Kamrul, and Indra Gunawan. "Analysis of Cost and Schedule Performance of International Development Projects." International Journal of Project Management 28, no. 1 (January 1, 2010): 68-78. https://doi.org/10.1016/j.ijproman.2009.03.005. 